\title{
CORRELATION BETWEEN SYMPTOM SEVERITY AND OBJECTIVE PARAMETERS IN ELDERLY MEN WITH LOWER URINARY TRACT SYMPTOMS
}

\author{
Bhomi KK, Joshi BR
}

Department of Urology, Nepal Medical College Teaching Hospital, Attarkhel, Gokarneshwor-8, Kathmandu, Nepal

\section{ABSTRACT}

Lower urinary tract symptoms (LUTS) are mostly due to benign prostate hyperplasia (BPH) in the elderly men. The severity of LUTS associated with BPH is measured with the international prostate symptom score (IPSS). Objective indicators of the disease severity in BPH are prostate volume, post void residual urine volume (PVRU), uroflowmetry values etc. However the correlation between the severity of subjective symptoms and objective parameters remains unclear. We designed this study to see if there actually is a correlation between the subjective symptoms and the objective parameters in evaluation of LUTS. Elderly male patients presenting with LUTS in the Urology OPD over a period of 10 months are enrolled in this study. These patients are asked to fill the IPSS with assistance if necessary from medical person. Prostate volume and PVRU are measured with trans-abdominal ultrasonography. Uroflowmetry evaluations are done to record maximum flow rate (Qmax) and average flow rate (Qave). Correlation of IPSS with age, prostate volume, PVRU and uroflowmetry parameters is evaluated using correlation regression analysis. Our results revealed significant positive correlation of IPSS with prostate volume and PVRU. Similarly there is significant negative correlation of IPSS with Qmax and Qave. Hence this study concluded that there is significant correlation between symptom severity and objective parameters in elderly patients with LUTS.

\section{KEYWORDS}

Correlation, LUTS, objective parameters

\section{CORRESPONDING AUTHOR}

Dr. Krishna Kaji Bhomi

Associate Professor,

Department of Urology,

Nepal Medical College Teaching Hospital,

Attarkhel, Gokarneshwor-8, Kathmandu, Nepal

Email: kkbhomi@hotmail.com 


\section{INTRODUCTION}

Lower urinary tract symptoms (LUTS) include storage and/or voiding disturbances and are mostly due to benign prostate hyperplasia (BPH) in elderly men. Management of BPH needs both subjective assessment of symptoms and objective documentation of measurable parameters. The severity of LUTS associated with BPH can be measured using a validated questionnaires such as the international prostate symptom score (IPSS). The IPSS is recommended as the symptom scoring instrument to be used for the baseline assessment of symptom severity in men presenting with LUTS..$^{1,2}$ However the IPSS can not be used to establish the diagnosis of BPH. A variety of lower urinary tract disorders like infection, neoplasm, neurogenic bladder disease may have a high IPSS.

Objective indicators of the disease severity in $\mathrm{BPH}$ are prostate volume, post void residual urine volume (PVRU) and uroflowmetry values including maximum flow rate (Qmax) and average flow rate (Qave). However, the correlation between the severity of subjective symptoms and value of objective parameters remains unclear. Hence we planned this study to analyze the correlation between IPSS and objective parameters in elderly men with LUTS.

\section{MATERIALS AND METHODS}

This is a prospective observational study done at Nepal Medical College Teaching Hospital, a tertiary care center in Kathmandu, Nepal. Ethical approval from Institutional Review Committee (approval number 001-074/075) was taken prior to starting the study. Minimum sample size for this study is calculated to be 95, taking the reference from previous study by Basri et al ${ }^{3}$ with correlation coefficient of -0.446 between IPSS and maximum flow rate using the sample size formula:

$\mathrm{n}=\mathrm{Z}^{2}\left(1-\mathrm{r}^{2}\right) / \mathrm{d}^{2}+2$
Elderly male patients presenting with LUTS to the urology outpatient department over a period of 10 months from August 2017 to May 2018 were included in the study. Exclusion criteria were patients with diagnosed urethral stricture, prostatic carcinoma, vesical stone, or neurogenic bladder dysfunction, patients who had undergone prior urinary tract or pelvic surgeries, and patients who could not void $\geq 150 \mathrm{ml}$ in uroflowmetry. Patients who are already on indwelling Foley's catheter or those taking medical treatment for BPH are also excluded.

In addition to clinical history taking and physical examination, patients fulfilling inclusion criteria were asked to fill the IPSS with assistance if necessary from medical person. Ultrasonography of abdomen was done to document prostate volume and PVRU. Uroflowmetry was performed using standard procedure protocol. Voided volume, Qmax and Qave were recorded. Uroflowmetry was repeated if the voided volume was less than $150 \mathrm{ml}$.

Patients were divided into three groups according to IPSS score: group I with IPSS 0-7, group II with IPSS 8-19 and group III with IPSS 20-35. Age, prostate volume, PVRU, Qmax and Qave were compared according to IPSS groups. The correlation between IPSS groups and these objective parameters was evaluated. Statistical analysis was done using SPSS version 16 and $p$ value $<0.05$ is considered as statistically significant.

\section{RESULTS}

Mean age of the patients was $64.09 \pm 10.92$ years. Mean total IPSS was $16.01 \pm 8.25$. According to IPSS scoring, among 95 patients, 22 had mild symptoms, 42 had moderate symptoms and 31 had severe symptoms. The mean prostate volume, PVRU, Qmax and Qave in patients with mild, moderate and severe symptoms were shown in Table 1.

Table 1: Distribution of age and objective parameters according to IPSS groups

\begin{tabular}{|lccc|} 
& Group I (n=22) & Group II (n=42)* & Group III (n=31)* \\
Age & $61.5 \pm 11.2$ & $62.7 \pm 9.7$ & $67.7 \pm 11.6$ \\
Prostate volume(ml) & $38.0 \pm 7.9$ & $46.3 \pm 10.1$ & $55.0 \pm 16.6$ \\
PVRU(ml) & $19.9 \pm 16.0$ & $51.1 \pm 64.2$ & $101.1 \pm 104.8$ \\
Qmax(ml/sec) & $20.8 \pm 4.8$ & $17.1 \pm 4.3$ & $10.0 \pm 2.9$ \\
Qave(ml/sec) & $10.2 \pm 3.2$ & $8.1 \pm 2.3$ & $5.1 \pm 1.9$ \\
QoL & $2.0 \pm 0.6$ & $2.7 \pm 0.7$ & $3.6 \pm 0.7$ \\
\hline
\end{tabular}

PVRU: Post void residual urine, Qmax: Maximum flow rate, Qave: Average flow rate, QoL: Quality of life

*mean $\pm S D$ 
Table 2: Correlation between IPSS and objective parameters

\begin{tabular}{|lcc|} 
& $\begin{array}{c}\text { Correlation } \\
\text { coefficient, } \mathbf{r}\end{array}$ & $\mathbf{p}$ \\
IPSS-Age & 0.203 & 0.083 \\
IPSS-prostate volume & 0.414 & 0.01 \\
IPSS-PVRU & 0.448 & 0.01 \\
IPSS-Qmax & -0.696 & 0.001 \\
IPSS-Qave & -0.648 & 0.001 \\
IPSS-QoL & 0.701 & 0.000 \\
\hline
\end{tabular}

IPSS: International prostate symptom score, PVRU: Post void residual urine, Qmax: Maximum flow rate, Qave: Average flow rate, QoL: Quality of life

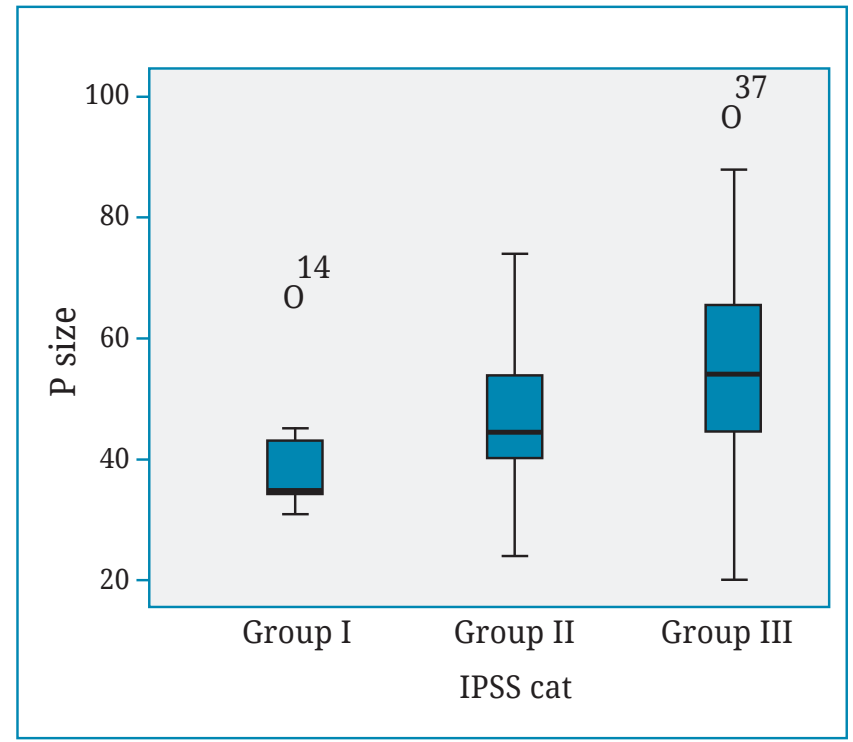

Fig. 1: Box plot showing prostate size in IPSS categories. P size: Prostate size, IPSS cat: IPSS category; O: Outlier

The correlations of IPSS with these individual objective parameters along with Pearson's correlation coefficient are shown in Table 2. The correlation between IPSS and age is statistically not significant ( $p>0.05)$ with correlation coefficient of 0.203 . Prostate volume and PVRU have significant positive correlation with IPSS, with correlation coefficient of 0.414 and 0.448 respectively. Similarly Qmax and Qave have significant negative correlation with IPSS, with correlation coefficient of -0.696 and -0.648 respectively. Among the evaluated parameters, Qmax has the strongest correlation with IPSS. Fig. 1 shows distribution of prostate volume among the IPSS categories and Fig. 2 shows distribution of Qmax in IPSS categories.

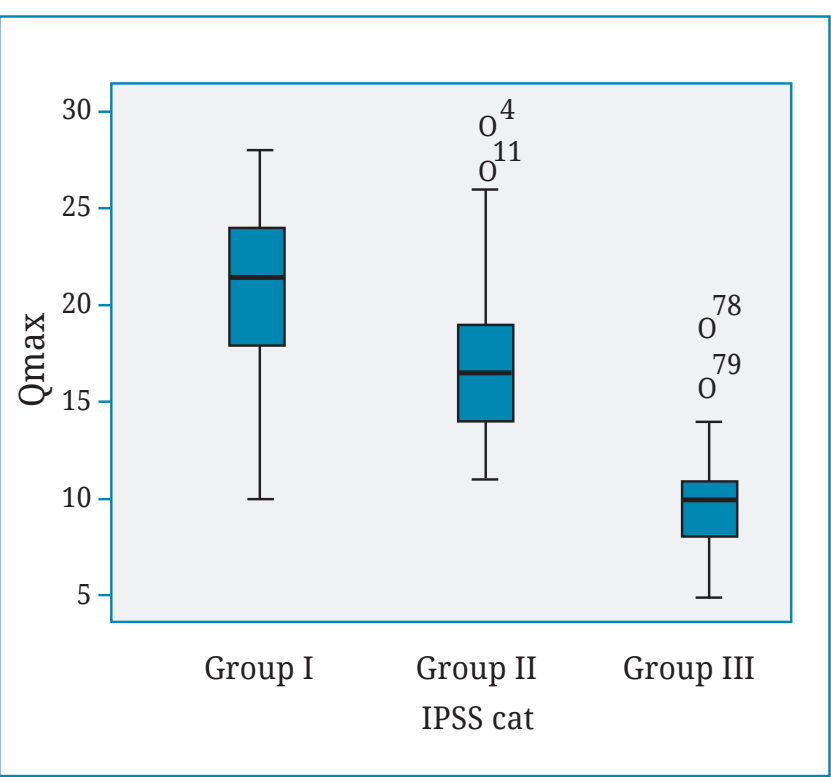

Fig. 2: Box plot showing Qmax in IPSS categories. Qmax: maximum flow rate, IPSS cat: IPSS category; O: Outlier

\section{DISCUSSION}

Lower urinary tract symptoms in elderly men due to $\mathrm{BPH}$ is evaluated using symptom scoring tools, the most common being IPSS which include weak stream, hesitancy, intermittency, incomplete voiding, urgency, frequency and nocturia. Higher the IPSS score, severe is the symptoms of the patient.

Several studies have shown that there are correlations between urinary symptoms and age, prostate volume, maximum flow rate, or residual urinary volume. ${ }^{3,4,5,6}$ However other studies have failed to show that these objective parameters can predict the severity of symptoms in BPH patients. . $^{7,8,9}$

The present study is designed to determine the relationship of IPSS with objective parameters used in the evaluation of BPH. Age of the patient did not have statistically significant correlation in this study with correlation coefficient $r=0.203$. This is in contrast to studies by Barsi et al and Itoh et al where they have shown a significant correlation of IPSS with age of the patients. ${ }^{3,7}$ Mean prostate size in our study is $47.2 \pm 13.6 \mathrm{gm}$. This is much higher than the mean prostate size of $40.1 \mathrm{~cm}^{3}$ measured by Vasely et al and $41 \mathrm{~cm}^{3}$ measured by Dicuio et al..$^{10,11}$ The larger size of the gland in our study may be due to late presentation of the patients in our setup. Patients tend to ignore minor symptoms and present to health service only when symptoms become severe.

We found significant correlation between IPSS and prostate volume as well as between IPSS and PVRU with coefficient of correlation $r=0.414$ and $\mathrm{r}=0.448$, respectively. In a study of 100 patients from eastern part of Nepal, IPSS was found to have 
a moderate positive correlation with prostate size, with correlation coefficient of $0.533 .{ }^{12}$ Similarly, statistically significant correlation has been found between symptom severity and PVRU in different studies. ${ }^{13,14}$ However, Barry et $a l^{15}$ reported no correlation between symptom severity and prostate size or PVRU and El Din et $a l^{16}$ found only a weak correlation among these parameters.

Although the gold standard for the diagnosis of bladder outlet obstruction is urodynamic studies, uroflowmetry is a simple, accurate and noninvasive method of assessing the dynamics of micturition. ${ }^{17,18}$ Maximum flow rate is the most important parameter in uroflowmetry study which is representative for severity of the degree of prostatic obstruction in BPH. ${ }^{19-21}$ Studies have shown statistically significant correlation of IPSS with Qmax and Qave. ${ }^{16,22,23}$
Itoh et $a l^{7}$ studied 206 males and concluded that average flow rate had highest correlation with symptom score while Singla et $a l^{14}$ found that Qmax is the most representative of the symptom severity of the patient. Our study also revealed significant negative correlation of IPSS with Qmax and Qave with correlation coefficient $\mathrm{r}=-0.696$ and $\mathrm{r}=-0.648$ respectively.

In conclusion, data obtained in the present study suggest that there is significant correlation between the subjective symptom severity and values of objective parameters in the evaluation of elderly male patients with LUTS due to BPH. Among the evaluated objective parameters, strongest correlation of IPSS was found with the Qmax, with correlation coefficient $\mathrm{r}=-0.696$.

\section{REFERENCES}

1. Kaplan SA. Update on the American Urological Association guidelines for the treatment of benign prostatic hyperplasia. Rev Urol 2006; 8 Suppl 4: S107.

2. Abrams P, Chapple C, Khoury S et al. Evaluation and treatment of lower urinary tract symptoms in older men. J Urol 2009; 181: 1779-87.

3. Basri C, Ramazan G, Orhun S et al. The correlation of symptoms severity and objective measures in patients with lower urinary tract symptoms. Clin Med Res 2013; 2: 135-9.

4. Madersbacher S, Klingler HC, Djavan B et al. Is obstruction predictable by clinical evaluation in patients with lower urinary tract symptoms? Brit J Urol 1997; 80: 72-7.

5. Barry MJ, Fowler FJ Jr, O'Leary MP et al. The American Urological Association symptom index for benign prostatic hyperplasia. The Measurement Committee of the American Urological Association. J Urol 1992; 148: 1549-57.

6. Wang JY, Liu M, Zhang YG et al. Relationship between lower urinary tract symptoms and objective measures of benign prostatic hyperplasia: a Chinese survey. Clin Med J 2008; 121: 2042-5.

7. Itoh H, Kojima M, Okihara $\mathrm{K}$ et al. Significant relationship of time-dependent uroflowmetric parameters to lower urinary tract symptoms as measured by the International Prostate Symptom Score. Int'l J Urol 2006; 13: 1058-65.

8. Tubaroa A, Vecchia CA. The relation of lower urinary tract symptoms with life-style factors and objective measures of benign prostatic enlargement and obstruction: an Italian survey. Eur Urol 2004; 45: 767-72.
9. Kezzeldin LA, Kiemeney LA, de Wildt MJ, Debruyne FM, de la Rosette JJ. Correlation between uroflowmetry, prostate volume, postvoid residue, and lower urinary tract symptoms as measured by the international prostate symptom score. Urology 1996; 48: 393-7.

10. Vesely S, Knutson T, Damber JE et al. Relationship between age, prostate volume, prostate-specific antigen, symptom score and uroflowmetry in men with lower urinary tract symptoms. J Urol Nephrol 2003; 37: 322-8.

11. Dicuio M, Pomara G, Vesely S et al. The use of prostatic intravesical protrusion correlated with uroflowmetry: a new method to measure obstruction in patients with LUTS due to BOO without using P/F studies. Arch Ital Urol Androl 2005; 77: 50-3.

12. Thapa N, Agrawal CS. Correlation of uroflowmetry with lower urinary tract symptoms in patients with symptomatic benign prostatic hyperplasia at eastern part of Nepal: A prospective study. IOSR-J Dental Med Sci 2017; 16: 86-91.

13. Kolman C, Girman CJ, Jacobsen SJ, Lieber MM. Distribution of post-void residual urine volume in randomly selected men. J Urol 1999; 161: 122-7.

14. Singla S, Garg R, Singla A, Sharma S, Singh J, Sethi P. Experience with uroflowmetry in evaluation of lower urinary tract symptoms in patients with benign prostatic hyperplasia. J Clin Diagn Res 2014; 8: 1-3.

15. Barry M, Coccket A, Holtgroove EN. Relationship of symptoms of prostatism to commonly used physiological and anatomical measures of severity of BPH. J Urol 1993; 150: 351-8. 
16. El Din KE, Kiemeney L, Wildt MD, Debruyne FMJ, De La Rosette JMC. Correlation between uroflowmetry, prostate volume, postvoid residue, and lower urinary tract symptoms as measured by the international prostate symptom score. Urology 1996; 48: 393-7.

17. Abrams PH. Prostatism and prostatectomy: The value of urine flow rate measurement in the preoperative assessment for operation. J Urol 1977; 117: 70-1.

18. Nitti VW. Pressure flow urodynamic studies: The gold standard for diagnosing bladder outlet obstruction. Rev Urol 2005; 7: S14-21.

19. Nordling J. Curriculum in urology urodynamics including incontinence and BPH: Urodynamics of BPH. Eur Urol 1998; 34: 1-8.

20. Homma Y, Kawabe K, Tsukamoto T et al. Estimate criteria for efficacy of treatment in benign prostatic hyperplasia. Int'l J Urol 1995; 3: 267-73.
21. Shroukry I, Susset JG, Moustafa M. Role of uroflowmetry in the assessment of lower urinary tract obstruction in adult males. Brit J Urol 1975; 47: 559-66.

22. Bosch JLHR, Hop WCJ, Kirkels WJ, Schrosber FH. The International Prostate Symptom Score in a community based sample of men between 55 and 74 years of age; prevalence and correlation of symptoms with age, prostate volume, flow rate and residual urine volume. Brit J Urol 1995; 75: 622-30.

23. Oranusi CK, Nwofor AE, Mbonu O. Correlation between international prostate symptom score and uroflowmetry in patients with benign prostatic hyperplasia. Niger J Clin Pract 2017; 20: 454-8. 